\title{
Aplikasi Zat Pengatur Tumbuh Dan Kegiatan Pruning Dalam Optimalisasi Budidaya Gaharu Di Desa Duman Kecamatan Lingsar Lombok Barat
}

\author{
I Gde Adi Suryawan Wangiyana ${ }^{a^{*}}$, Dina Soes Putri ${ }^{\mathrm{b}}$ \\ aFakultas IImu Kehutanan Universitas Nusa Tenggara Barat, Indonesia \\ ${ }^{b}$ Fakultas Pertanian Universitas Muhammadiyah Mataram, Indonesia \\ ${ }^{\star}$ Corresponding author email: dede.consultant@gmail.com
}

\section{Diterima: Agustus 2019; Revisi: Oktober 2019; Diterbitkan: November 2019}

\begin{abstract}
Abstrak
Tujuan dari pengabdian masyarakat ini adalah untuk memberikan pembinaan bagi para petani Desa Duman khususnya istri mereka untuk mengoptimalkan pertumbuhan pohon gaharu mereka melalui aplikasi pendorong pertumbuhan dan pemangkasan. Peserta pengabdian masyarakat ini adalah istri Petani Desa Duman. Pengabdian masyarakat ini diawali dengan sosialisasi tentang pentingnya mendorong pertumbuhan dan pemangkasan pada budidaya gaharu. Kemudian, para peserta diberi kesempatan untuk mempraktekkan teori yang mereka peroleh dari sosialisasi. Fitohormon giberelin adalah penginduksi pertumbuhan yang digunakan dalam kegiatan ini. Dosis fitohormon tersebut adalah $1 \mathrm{gr}$ untuk 2 liter air. Pemangkasan dilakukan dengan menebang cabang pucuk pohon gaharu menggunakan gunting tanaman. Daun dari cabang yang sudah dipotong pada kegiatan pemangkasan dapat diolah menjadi teh gaharu. Dapat disimpulkan bahwa peserta telah memahami tentang penerapan pendorong pertumbuhan dan pemangkasan untuk mengoptimalkan pertumbuhan pohon gaharu.
\end{abstract}

Kata Kunci: ZPT; Pruning; Gaharu; Desa Duman

\section{Application of Growth Regulators and Pruning Activities in Optimizing Agarwood Cultivation in Duman Village, Lingsar District, West Lombok}

\begin{abstract}
The aim of this community service is to give training for farmers of Duman Village, especially their wife, to optimize growth of their agarwood tree by application of promoting growth inducer and pruning. The participants on this community service were Farmers's wife of Duman Village. This community service started by socialization about the important of promoting growth inducer and pruning activity on agarwood cultivation. Then, the participants were given an opportunity to practice the theory that they got from the socialization. Gibberellins phytohormone was the promoting growth inducer that was used in this activity. The dose of that phytohormone was $1 \mathrm{gr}$ for 2 liter water. Pruning activity was conducted by cutting top branch of agarwood tree using plant scissors. Leaves from branch that has been cut on the pruning activity could be processed to produce agarwood tea. It could be concluded that participant has already understood about application of promoting growth inducer and pruning activity to optimize growth of agarwood tree.
\end{abstract}

Keywords: ZPT; Pruning; Gaharu; Desa Duman

How to Cite: Wangiyana, I., \& Putri, D. (2021). Aplikasi Zat Pengatur Tumbuh Dan Kegiatan Pruning Dalam Optimalisasi Budidaya Gaharu Di Desa Duman Kecamatan Lingsar Lombok Barat. Lumbung Inovasi: Jurnal Pengabdian kepada Masyarakat, 4(2), 36-42. doi:https://doi.org/10.36312/linov.v4i2.452

d. https://doi.org/10.36312/linov.v4i2.452

\section{PENDAHULUAN}

Desa Duman merupakan salah satu desa di Kecamatan Lingsar yang menjadi sentra pertanian dan perkebunan di Kabupaten Lombok Barat. Di desa ini sebagian besar 
penduduknya berprofesi sebagai petani. Komoditas perkebunan merupakan komoditas tambahan yang juga dikembangkan oleh petani Desa Duman sebagai tambahan dari komoditas pertanian yang merupakan mata pencaharian pokok mereka.

Pohon gaharu (Gyrinops versteegii) merupakan salah satu komoditas perkebunan yang banyak terdapat pada areal persawahan petani desa Duman. Pohon gaharu tersebut merupakan satu diantara beberapa tanaman pohon yang menjadi komoditas perkebunan mereka. Sayangnya petani Desa Duman tidak menyadari bahwa pohon gaharu tersebut merupakan komoditas bernilai ekonomis tinggi. Bahkan produk ini merupakan produk ekspor yang sangat laku di perdagangan global. (Lopez-Sampson \& Page, 2018).

Kurangnya pemahaman petani terkait tingginya nilai komoditas gaharu terlihat dari kondisi fisik pohon gaharu di perkebunan mereka. Ratarata diameter dan tinggi batang pohon gaharu mereka jauh dibawah standar. Hal ini tidak memungkinkan untuk dilakukannya kegiatan bioinduksi bagi pohon gaharu tersebut agar layak untuk dipanen. Proses bioinduksi tersebut membutuhkan diameter batang minimal $10 \mathrm{~cm}$ (Wangiyana et al. 2018).

Terdapat paling tidak dua permasalahan mendasar mengapa pohon gaharu di perkebunan gaharu desa Duman tidak tumbuh dengan optimal. Yang pertama adalah petani Desa Duman menganggap bahwa tanaman gaharu yang memiliki habitus pohon, tidak membutuhkan perawatan khusus seperti layaknya tanaman pertanian. Yang kedua, petani Desa Duman tidak memiliki cukup waktu luang untuk mengurus pohon gaharu di perkebunan mereka.

Permasalahan pertama dapat diatasi dengan aplikasi zat pengatur tumbuh (ZPT) dan metode pruning dalam budidaya gaharu di Desa Duman. ZPT merupakan senyawa yang mampu memacu pertumbuhan organ tamanan dan merupakan faktor penting dalam keberhasilan budidaya tanaman. Bahan ini bahkan harus diaplikasikan untuk budidaya gaharu secara in-vitro (Saikia et al. 2012). Sementara itu, metode pruning merupakan salah satu cara untuk mengoptimalkan pertumbuhan batang tanaman pohon sehingga memiliki diameter dan tinggi yang optimal (Goodfellow et al. 1987). Metode pruning ini juga merupakan metode baku yang digunakan oleh petani gaharu di Tiongkok (Liu et al. 2013).

Permasalahan kedua dapat diatasi dengan memberi pelatihan kepada istri petani Desa Duman. Sebagian besar istri petani di Desa Duman berprofesi sebagai ibu rumah tangga. Mereka mempunyai cukup banyak waktu luang untuk digunakan dalam budidaya pohon gaharu. Selain Selain itu, aplikasi ZPT dan metode pruning tergolong pekerjaan yang ringan sehingga cocok untuk dilakukan oleh para wanita.

Berdasarkan hal tersebut, kegiatan pengabdian kepada masyarakat ini bertujuan untuk melakukan pelatihan kepada para istri petani Desa Duman untuk melakukan kegiatan aplikasi ZPT dan pruning dalam rangka mengoptimalkan pertumbuhan pohon gaharu yang ada di kebun mereka.

\section{METODE PELAKSANAAN}

Partisipan dalam kegiatan pengabdian kepada masyarakat ini adalah istri petani Desa Duman, Kecamatan Lingsar Kabuptaen Lombok Barat. Jumlah partisipan adalah sebanyak 20 orang. Seperti yang telah dijelaskan sebelumnya, pemilihan istri petani sebagai partisipan terkait dengan profesi mereka sebagai ibu rumah tangga sehingga memiliki cukup banyak waktu luang. Disatu sisi, mereka ingin agar waktu luang tersebut digunakan untuk kegiatan yang sifatnya produktif karena sebagian besar mereka memang berada dalam usia produktif. Oleh karena itulah, pelatihan yang bertujuan untuk menjadikan mereka mandiri dan mampu berwirausaha merupakan suatu pilihan yang tepat (Sugiyana dkk. 2017)

Kegiatan pengabdian ini dilakukan di areal persawahan desa Duman, Kecamatan Lingsar Kabupaten Lombok Barat. Metode yang digunakan adalah metode ceramah dan praktik secara langsung. Oleh karena itu kegiatan pengabdian ini dibagi menjadi dua tahap utama yaitu: tahap teori dan tahap praktek (Cooks and Scharrer, 2006). Selain itu terdapat pula tahap evaluasi yang bertujuan untuk menilai tingkat keberhasilan pelaksanaan program.

\section{Tahap Teori}

Pada tahap teori, partisipan diberikan sosialisasi terkait pentingnya melakukan budidaya gaharu. Penekanan bahwa gaharu merupakan komoditas bernilai ekonomis tinggi digunakan 
untuk memacu semangat partisipan dalam melakukan kegiatan. Dengan demikian mereka dapat lebih antusias mengikuti setiap tahap dalam kegiatan.

Pada tahap teori ini, partisipan juga diberikan teori tentang zat pengatur tumbuh dan metode pruning. Teori diberikan secara bertahap untuk mengantisipasi pengetahuan partisipan yang masih minim terkait materi yang diberikan. Selain itu, dalam materi pelatihan juga banyak diberikan gambar dan video interaktif untuk lebih memudahkan partisipan memahami materi yang diberikan.

\section{Tahap Praktik}

Pada tahap praktik, partisipan diberi kesempatan untuk menerapkan teori yang telah mereka terima sebelumnya. Pada tahap ini, pemahaman partispan terkait materi yang diberikan benar - benar akan diuji. Keberhasilan partisipan melalui tahap ini sangat mendukung kemandirian mereka dalam melanjutkan kegiatan setelah proses pendampingan oleh tim pengabdian kepada masyarakat selesai dilakukan.

Dalam kegiatan praktek aplikasi ZPT digunakan fitohormon Giberelin. Giberelin merupakan fitohormon yang mampu memacu pertumbuhan memanjang dari batang tanaman. Selain itu, fitohormon ini juga dikenal sebagai senyawa antikerdil sehingga mengoptimalkan pertumbuhan tamanan pohon (Brian, 2008). Fitohormon ini diberikan dalam bentuk merek dagang "GibPro". Dosis pemberian Giberalin adalah sebesar 1 gr per 2 liter air. Untuk lebih memudahkan partisipan dalam melakukan kegiatan, tim pengabdian kepada masyarakat menggunakan giberelin dalam bentuk sachet $1 \mathrm{gr}$ sehingga partisipan tidak perlu melakukan penimbangan.

Aplikasi giberelin dilakukan secara rutin minimal 2 kali dalam sebulan. Penyemproatan giberelin difokuskan pada organ daun. Hal ini karena bagian daun merupakan organ yang difokuskan untuk berkembang dengan baik. Ketika organ daun pada cabang tumbuh dengan baik, dilakukan pemangkasan sekaligus memanen daun tersebut.

Dalam kegiatan praktik metode pruning, dilakukan pemangkasan cabang teratas dari pohon gaharu dengan menggunakan gunting tanaman. Pemangkasan tersebut dapat memacu pertumbuhan batang utama. Pertumbuhan tersebut baik dari segi diameter batang dan juga tinggi batang.

Daun hasil pemangkasan dalam kegiatan pruning dapat diolah menjadi teh herbal. Teh tersebut dikenal sebagai teh gaharu. Dengan demikian terjadi kesinambungan yang berkelanjutan. Daun diberi ZPT hingga tumbuh dengan baik, kemudian dipangkas untuk dipanen yang memungkinkan batang utama tumbuh lebih baik.

Dalam tahap praktek ini, tim pengusul bersama partisipan juga melakukan penanaman bibit gaharu di lahan partisipan. Bibit gaharu tersebut diharapkan dapat tumbuh dengan baik karena mendapat perlakuan pemberian ZPT. Selain itu perawatan yang intensif juga telah diajarkan pada partisipan sehingga mereka bisa langsung menerapkannya pada bibit tersebut. Dengan perawatan yang baik, bibit tersebut diharapkan dapat menjadi investasi jangka panjang bagi partisipan.

\section{Tahap Evaluasi}

Pada tahap ini tim pengusul melakukan evaluasi terhadap keberhasilan program yang telah dilaksanakan. Evaluasi tersebut untuk mengukur perubahan yang terjadi pada partisipan sebelum dan sesudah program. Perubahan yang diukur meliputi: perubahan tingkat pengetahuan partisipan serta perubahan keterampilan partisipan terkait materi yang telah diberikan. Perubahan tersebut secara kuantitatif dinilai dengan memberikan pre-test dan posttest terhadap partisipan sebelum dan sesudah pelaksanaan program.

\section{HASIL DAN PEMBAHASAN}

Berdasarkan hasil survei yang dilakukan oleh tim pengabdian kepada masyarakat, pohon gaharu di kebun mitra rata - rata memiliki diameter batang kurang dari $5 \mathrm{~cm}$ (Gambar 1). Padahal usia rata - rata pohon gaharu tersebut sudah mencapai 2 tahun. Hal ini mengindikasikan kurang optimalnya pertumbuhan pohon gaharu tersebut. Untuk itulah perlu dilakukan upaya optimalisasi pertumbuhan pohon gaharu melalui aplikasi zat pengatur tumbuh dan metode pruning. 


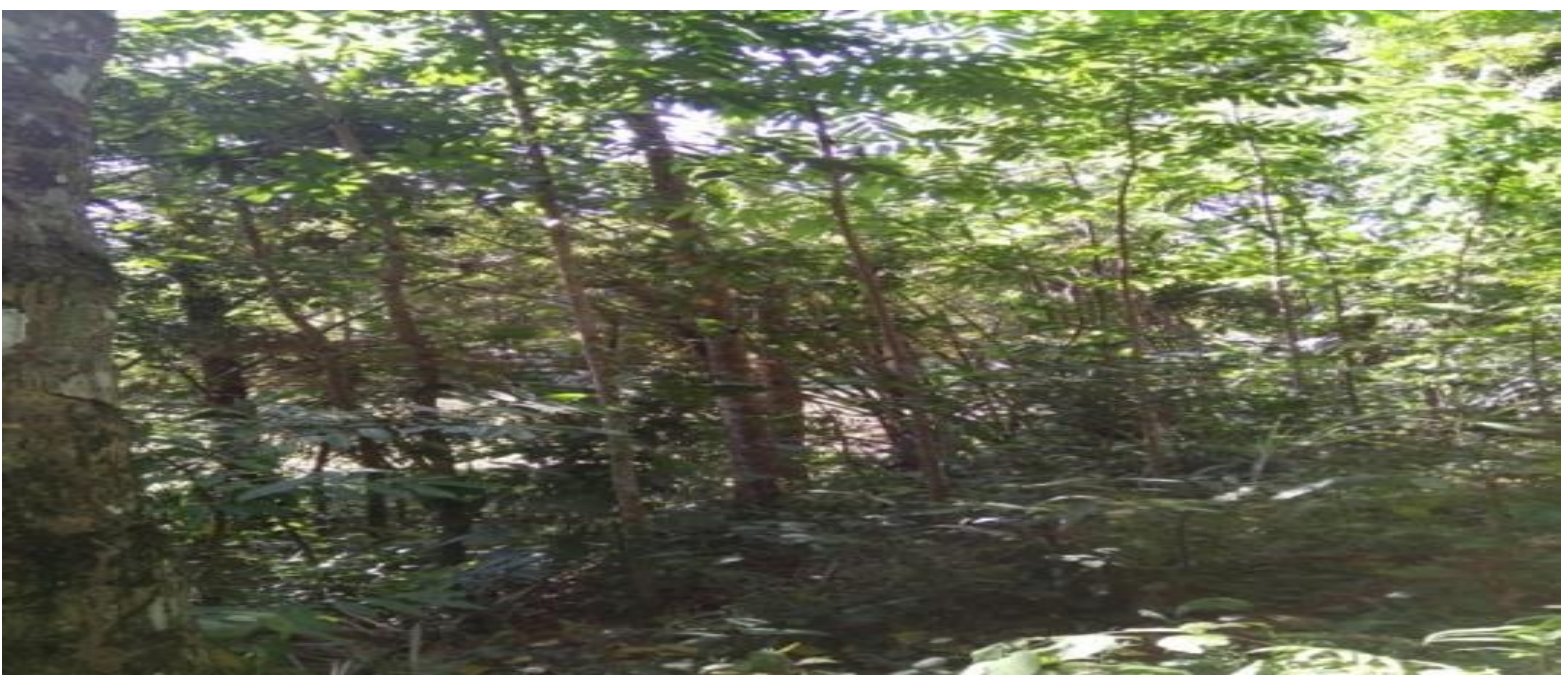

Gambar 1. Kondisi Pohon Gaharu Di Desa Duman

Partisipan dalam kegiatan ini adalah istri petani Desa Duman. Sebagai ibu rumah tangga, mereka memiliki cukup banyak waktu luang. Keinginan mereka yang kuat untuk turut membantu suami dalam menafkahi keluarga, membuat partisipan termotivasi untuk mengikuti kegiatan pelatihan ini. Disamping itu, mereka sangat berharap pada investasi jangka panjang dari pohon gaharu yang ada dikebun mereka.

Partisipan selalu antusias dalam mengikuti setiap kegiatan selama sosialisasi berlangsung (Gambar 2). Mereka juga tidak ragu mengajukan pertanyaan terkait materi yang belum mereka pahami. Karena pada dasarnya mereka memiliki pengetahuan bercocok tanam sebagai petani, maka materi dalam sosialisasi cukup mudah untuk mereka pahami.

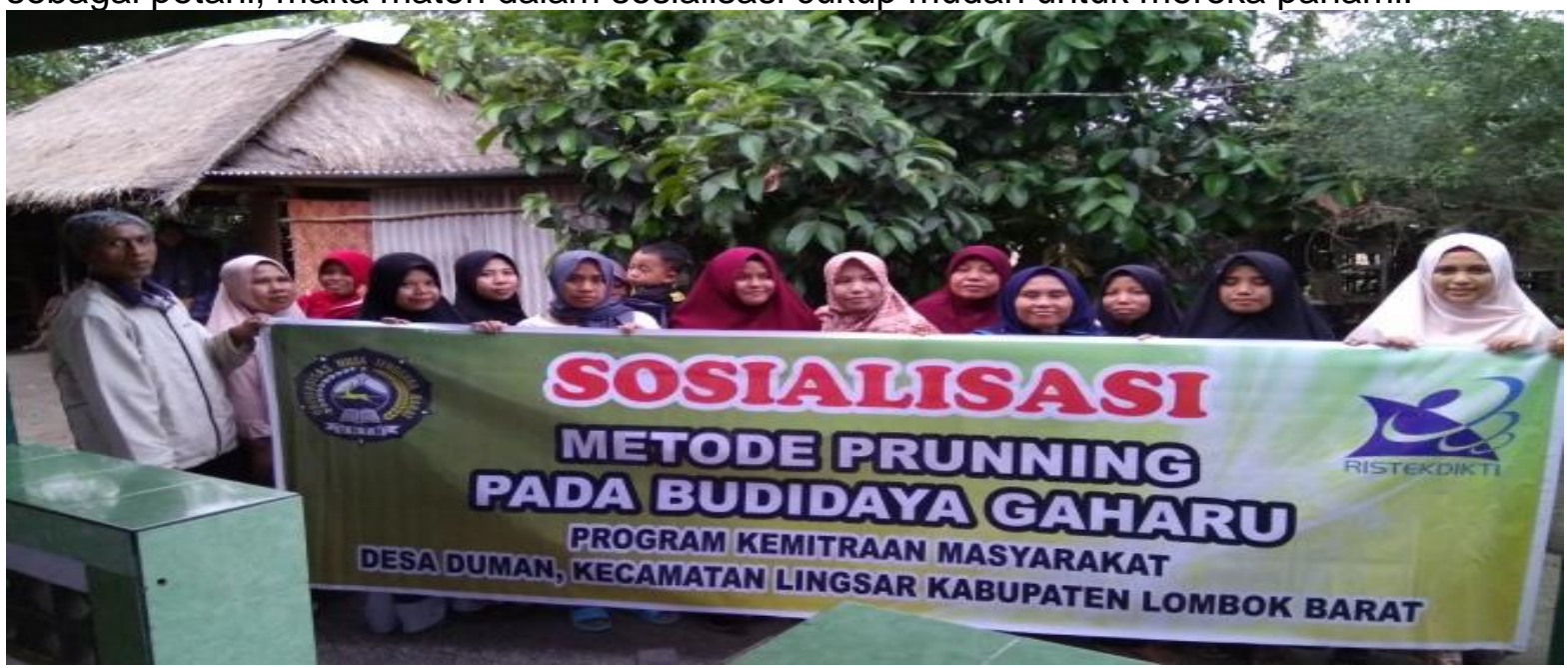

Gambar 2. Kegiatan Sosialisasi Metode Pruning.

Perubahan paling mendasar yang dialami oleh partisipan pasca kegiatan sosialisasi adalah berubahnya paradigma mereka terkait budidaya tanaman pohon seperti gaharu. Sebelum mengikuti sosialisasi, mereka menganggap bahwa tanaman pohon tidak memerlukan perawatan khusus, seperti pemupukan dan perawatan hama penyakit. Selama ini mereka menganggap bahwa hanya tanaman semusim yang merupakan komoditi pertanian saja yang membutuhkan perwatan khusus seperti itu. Mereka menganggap tanaman pohon merupakan tanaman liar sehingga dapat bertahan hidup tanda adanya campur tangan manusia.

Aplikasi Zat pengatur tumbuh (ZPT) menggunakan hromon giberalin untuk memacu pertumbuhan batang. Aplikasi ZPT tersebut menggunakan metode yang sangat sederhana sehingga mudah dipahami dan dipraktekkan oleh mitra. ZPT diberikan oleh tim pengabdian kepada masyarakat dalam bentuk sachet sekali pakai. Takarannya pun juga disesuaikan dengan sprayer yang digunakan oleh partisipan (Gambar 3). Aplikasi rutin ZPT minimal 2 kali 
dalam satu bulan terbukti mampu menyehatkan tanaman gaharu. Hal ini terlihat dari kondisi organ daun dan batang yang lebih segar dibandingkan dengan sebelum diberikan ZPT.

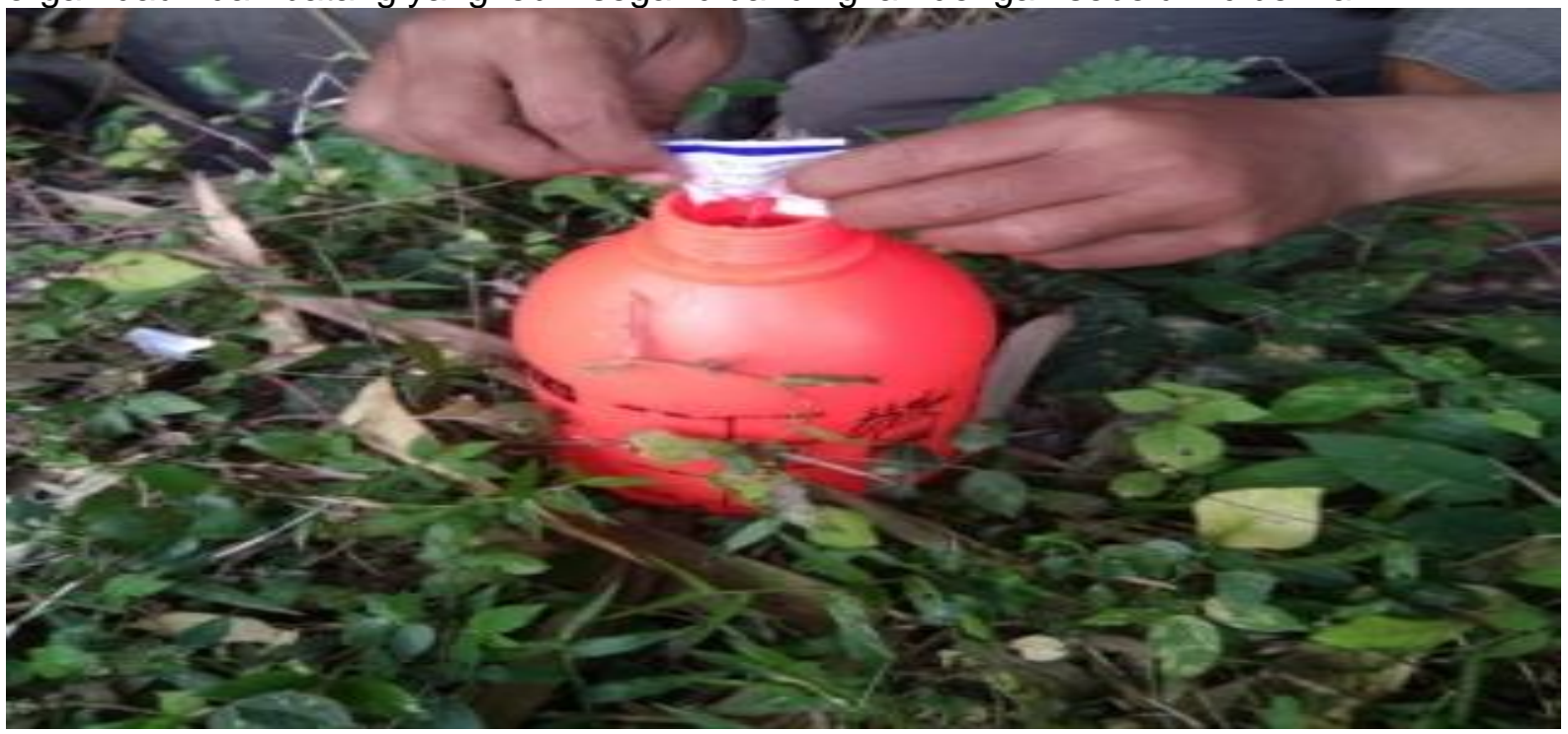

Gambar 3. Pembuatan larutan Zat Pengatur Tumbuh GibPro

Aplikasi ZPT GibPro dilakukan sebelum kegiatan pruning pada ranting cabang pohon gaharu (Gambar 4). Aplikasi ZPT ini mampu membuat daun terlihat lebih segar sbelum dipangkas. Selain itu, daun juga tumbuh lebih baik dibandingkan dengan tidak ada aplikasi ZPT. Bagian cabang yang dipangkas selanjutnya diambil daunnya. Daun tersebut dapat diolah untuk dijadikan minuman herbal teh gaharu (Wangiyana et al. 2018)

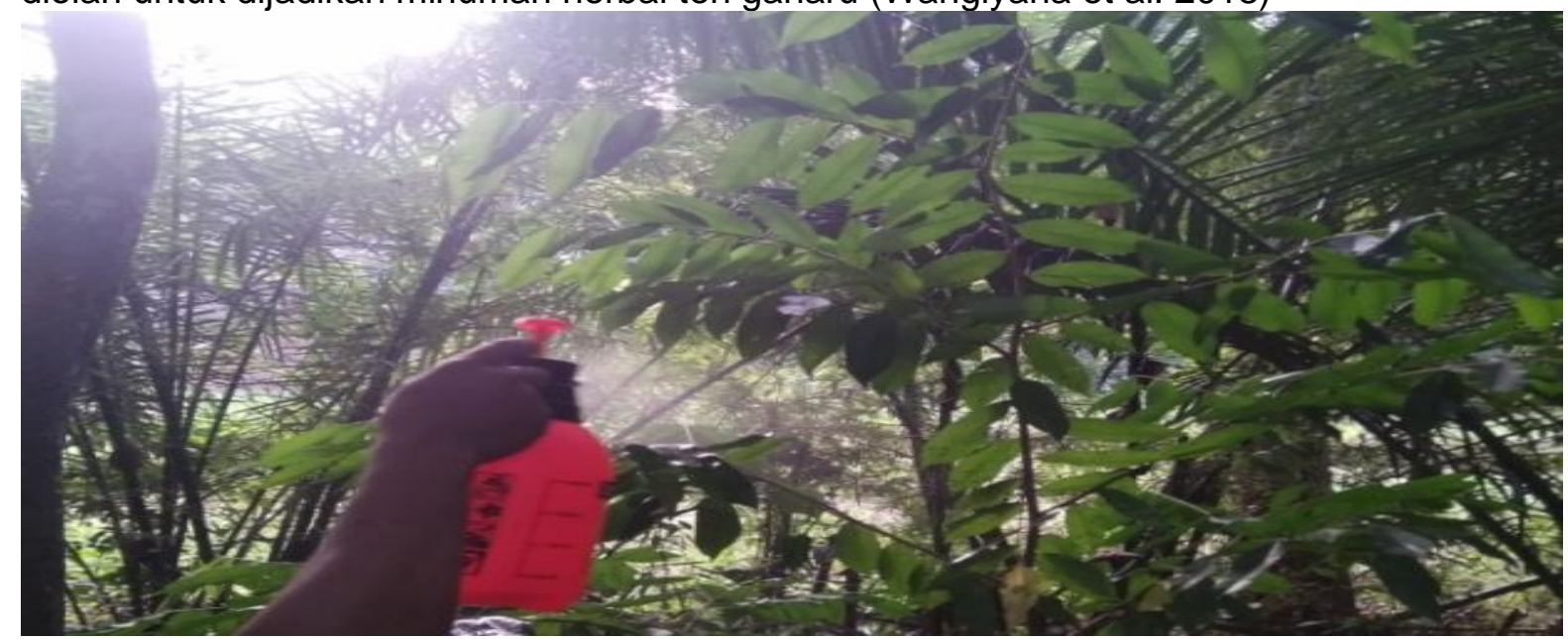

Gambar 4. Aplikasi GibPro dengan cara penyemprotan

Penanaman bibit gaharu merupakan bentuk kegiatan yang beriorientasi pada investasi bagi partisipan. Bibit gaharu yang ditanam adalah bibit berkualitas yang diperoleh dari sentra pembibitan gaharu di daerah Kekait Puncang (Wangiyana dan Wanitaningsih, 2018). Bibit ini rata-rata telah memiliki diameter $1-2 \mathrm{~cm}$ dengan tinggi $30 \mathrm{~cm}$. Dengan perawatan yang optimal, maka bibit tersebut sudah siap untuk mendapat perlakukan bioinduksi dalam waktu 6-10 tahun yang akan datang. Dengan perlakuan Bio-induksi, pohon gaharu tersebut sudah siap dipanen untuk diambil bagian resin yang terdapat pada batang minimal pada usia tanam 12 tahun (Akter et al. 2013).

Jangka waktu investasi minimal 12 tahun tersebut merupakan jangka waktu investasi yang cukup lama. Namun berdasarkan perhitungan partisipan, dalam waktu 12 tahun yang akan datang, rata - rata anak mereka telah selesai menempuh pendidikan dasar. Dalam hal ini, anak mereka memasuki tahapan pendidikan lanjutan yang umumnya membutuhkan dana cukup banyak. Jadi, waktu investasi minimal 12 tahun tersebut tidak menjadi masalah bagi partisipan. Bahkan waktu tunggu tersebut merupakan waktu yang paling tepat bagi mereka 
untuk memanen hasil karena berepatan dengan waktu mereka menyekolahkan anak mereka di tingkat pendidikan tinggi.

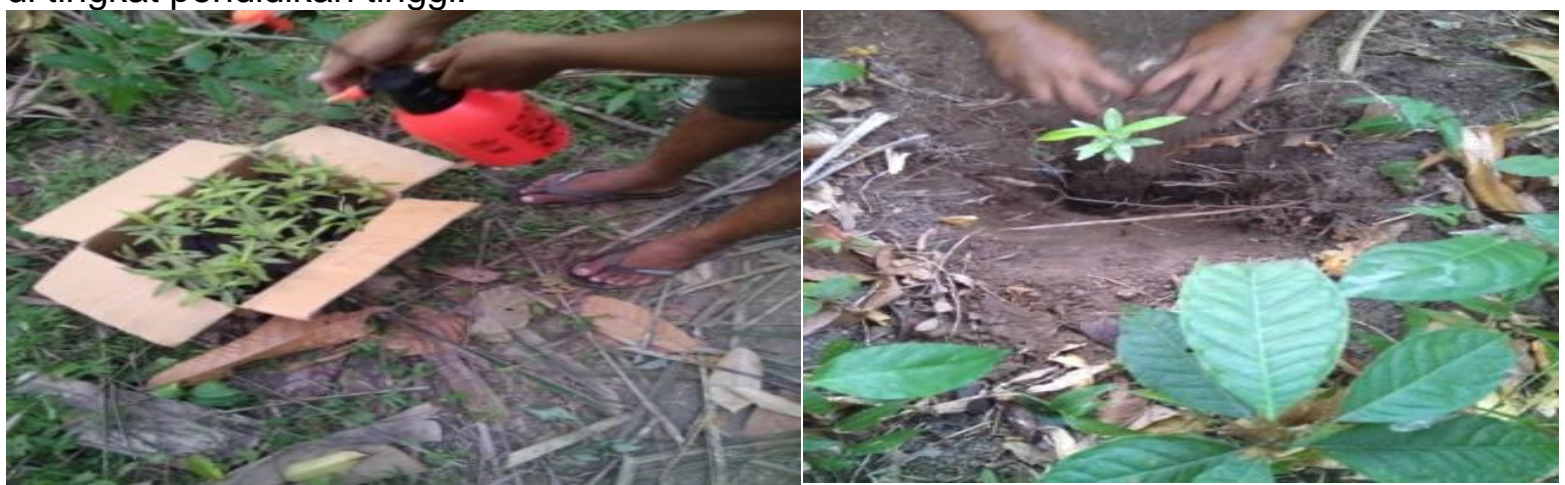

Gambar 5. Penanaman bibit gaharu di kebun partisipan

Tabel 1. Hasil Evaluasi Program

\begin{tabular}{|c|c|c|c|}
\hline Parameter yang diukur & pre-test & post-test & Peningkatan \\
\hline Pemahaman tingginya nilai ekonomi komoditi gaharu & $50 \%$ & $100 \%$ & $50 \%$ \\
\hline $\begin{array}{l}\text { Pemahaman pentingnya perawatan pada tanaman } \\
\text { pohon }\end{array}$ & $0 \%$ & $90 \%$ & $90 \%$ \\
\hline $\begin{array}{l}\text { pemahaman mengenai investasi dalam bentuk pohon } \\
\text { gaharu }\end{array}$ & $0 \%$ & $90 \%$ & $90 \%$ \\
\hline keterampilan melakukan pruning & $20 \%$ & $90 \%$ & $70 \%$ \\
\hline keterampilan mengaplikasikan ZPT & $10 \%$ & $90 \%$ & $80 \%$ \\
\hline Keterampilan melakukan penanaman bibit gaharu & $50 \%$ & $90 \%$ & $40 \%$ \\
\hline erata & & & $70 \%$ \\
\hline
\end{tabular}

Berdasarkan hasil evaluasi yang dilakukan oleh tim pengabdian kepada masyarakat, telah terjadi peningkatan pemahaman dan keterampilan partisipan sebesar rata-rata $70 \%$. Hal ini menggambarkan bahwa tingkat keberhasilan dari program yang telah dilaksanakan cukup tinggi. Peningkatan paling pesat adalah terletak pada peningkatan pemahaman partisipan mengenai pentingnya perawatan tanaman pohon dan juga peningkatan pemahaman mengani adanya bentuk investasi jangka panjang dalam bentuk pohon gaharu. Pada masing-masing parameter tersebut telah terjadi peningkatan sebesar $90 \%$. Melalui program pengabdian kepada masyarakat ini, partisipan menjadi lebih sadar akan pentingnya komoditi gaharu yang mereka miliki sehingga mereka semakin antusias untuk mengembangkan komoditi tersebut. Terlebih lagi, hasil kegiatan pruning berupa pemangkasan daun dapat mereka olah sebagai bahan baku minuman teh herbal sehingga dapat dijadikan sebagai pemasukan tambahan selama masa tunggu investasi 12 tahun terhadap pohon gaharu yang mereka miliki

\section{KESIMPULAN}

Bersadarkan temuan-temuan di atas dapat disimpulkan bahwa Mitra kegitan memahami sepenuhnya tentang metode optimalisasi pertumbuhan pohon gaharu melalui aplikasi zat pengatur tumbuh dan metode pruning baik secara teori maupun praktek.

\section{REKOMENDASI}

Kegitan Pendampingan perlu dilakukan secara kontinu agar mitra banar-benar mandiri dalam menerapkan metode pruning, selain itu perlu dilatih teknik pemanenan dan pemsasaran.

\section{UCAPAN TERIMAKASIH}

Terima kasih diucapkan kepada Ristekdikti atas pendanaan sehingga Program Kemitraan Masyarakat ini dapat terlaksana. diucapkan terima kasih pula untuk LLDIKTI Wilayah VIII yang telah memberikan informasi bermanfaat terkait pelaksanaan program. Yang 
terakhir adalah terima kasih untuk LPPM UNTB yang telah memfasilitasi Program Kemitraan Masyarakat ini dari tahap awal pengusulan proposal hingga pelaporan akhir.

\section{DAFTAR PUSTAKA}

Akter, S., Islam, M.D. Zulkefeli, M., Khan, S. I. (2013). Agarwood Production a Multidiciplinary Field to be Explored in Bangladesh. International Journal of Pharmaceutical and life science. 2 (1): $22-32$.

Brian, P. W. A. (2008). Effects of Gibberellins on Plants Growth and Development. Biological Reviewes. 34 (1): $37-77$.

Cooks, L. and Scharrer, E. (2006). Assessing Learning in Community Service Learning: A Social Approach. Michigan Journal of Community Service Learning. (2006): 44 - 55.

Goodfellow, W., Blumreich, B., Nowacki, G. (1987). Tree Growth Response to Line Clearance Pruning. Journal of Arboriculture. 13 (8): $196-200$.

Liu, Y., Chen, H., Yang, Y., Zhang, Z., Wei, J., Meng, H., Chen, W., Feng, J., Gan, B., Chen, X., Gao, Z., Huang, J., Chen, B., Chen, H. (2013). Whole-tree Agarwood-Inducing Technique: An Efficient Novel Technique for Producing High-Quality Agarwood in Cultivated Aquilaria sinensis Trees. Molecules. 18 (2013): 3086 - 3106.

Lopez-Sampson, A. and Page, T. (2018). History of Use and Trade of Agarwood. Economic Botany. 71 (1): $107-129$

Saikia, M., Shrivastava, K., Singh, S. (2012). An Efficient Protocol for Callus Induction in Aquilaria malaccensis Lam. Using Leaf Explants at Varied Concentration of Sucrose. International Journal of Plant Research. 2 (6): 188 - 194.

Sugiyani, Y., Ai Munandar, T. B., Harsiti. (2017). Pemberdayaan Ibu Rumah Tangga Usia Produktif Melalui Pembinaan Wirausaha Mandiri Mini Konveksi. Jurnal Pengabdian Kepada Masyarakat Wikrama Parahita. 1 (1): 32 - 39

Wangiyana, I G. A. S. dan Wanitaningsih, S. K., (2018). PKM Kelompok Pembibit Gaharu Desa Kekait Puncang Untuk Meningkatkan Efisiensi Produksi Bibit. Lumbung Inovasi. 3 (1): $52-58$.

Wangiyana, I G. A. S., Triandini, I G. A. A. H., Putradi, D., Wangiyana, W., (2018b). Tannin Concentration of Gyrinops Tea from Leaves of Juvenile and Mature Agarwood Trees (Gyrinops versteegii Gilg (Domke)) with Different Processing Methods. Journal of Chemical and Pharmaceutical Research. 10 (10): 113 - 119.

Wangiyana, I G. A. S., Wanitaningih, S. K., Sanjaya, A. (2018). Bioinduksi Gyirnops versteegii Menggunakan Inokulan Berbahan Baku Medium Tauge dengan Berbagai Kedalaman Pengeboran. Prosiding Seminar Nasional Pertanian, Matram, Januari 2018, hal. 144 152. 